\title{
Rompimento da barragem em Brumadinho: um relato de experiência sobre os debates no processo de desastres
}

\author{
Dam breaking in Brumadinho: an experience report on the debates in \\ the disaster process
}

Giulia Balbi Rodrigues da Costa1, Geórgia Rolemberg Lau1, Camilla Ferreira da Silva1, Maria Clara Barroso Mantel' , Maria Cristina Mitsuko Peres', Tatiane Nunes da Silva Santos Luna', Priscila

Neves da Silva ${ }^{2}$

DOI: 10.1590/0103-11042020E226

RESUMO O presente artigo teve como objetivo aprofundar discussões do desastre ocorrido em Brumadinho (MG), em janeiro de 2019. A partir da relatoria do seminário 'Desastre da Vale S.A. em Brumadinho: seis meses de impacto e ações’, seis alunas do Curso de Especialização em Saúde Pública da Fundação Oswaldo Cruz (Fiocruz) e uma pós-doutoranda da Fiocruz de Minas Gerais realizaram transcrições de falas feitas durante o evento na tentativa de reportar essa vivência mediante lugares de fala distintos. Experiências artísticas retratadas ao longo do texto estabelecem um vínculo com a subjetividade dos atingidos e seu entorno. Portanto, o artigo pretendeu seguir esse caminho.

PALAVRAS-CHAVE Desastre. Brumadinho. Mineração. Sistema Único de Saúde.

\begin{abstract}
The purpose of this article was to deepen discussions on the disaster that occurred in Brumadinho (MG), in January 2019. From the report of the seminar 'Disaster of Vale S.A. in Brumadinho: six months of impact and actions', six students from the Specialization Course in Public Health at Oswaldo Cruz Foundation (Fiocruz) and a postdoctoral fellow at Fiocruz in Minas Gerais performed transcriptions of speeches made during the event in an attempt to report this experience through different places of speech. Artistic experiences portrayed throughout the text establish a link with the subjectivity of those affected and their surroundings. Therefore, the article intended to follow that path.
\end{abstract}

KEYWORDS Disasters. Brumadinho. Mining. Unified Health System.

\footnotetext{
1 Fundação Oswaldo Cruz (Fiocruz), Escola Naciona de Saúde Pública Sergio Arouca (Ensp) - Rio de Janeiro (RJ), Brasil. giuliabalbicosta@gmail.com

2 Instituto René Rachou

- Fiocruz Minas - Belo

Horizonte (MG), Brasil.
} 


\section{Introdução}

No dia 25 de janeiro de 2019, rompeu-se a barragem B1, da mina Córrego do Feijão, de responsabilidade da Vale S.A. O rompimento levou a óbito, de imediato, 272 pessoas, entre as quais, 22 ainda não localizadas, além de expor ambiente e população às toxicidades presentes nos rejeitos de mineração.

A lama se estendeu por nove setores censitários do município, o que representa mais de $10 \%$ da população brumadinhense, incluindo comunidades tradicionais e agricultores. Ainda, impactou a biodiversidade, alterando ciclo de vetores e hospedeiros ${ }^{\mathbf{1}}$; inabilitou o Rio Paraopeba para consumo, irrigação, pesca, banho e lazer²; comprometeu de modo significativo a organização econômico-financeira do município, entre inumeráveis impactos que se sobrepõem e se incidem sobre a saúde de toda a população.

Esse é considerado o maior acidente de trabalho da história do País, tendo em vista que, ao fatídico horário de $12 \mathrm{~h} 28$, os trabalhadores estavam no refeitório quando foram surpreendidos. $\mathrm{O}$ fato de o refeitório e o prédio administrativo da empresa estarem implantados na rota da avalanche de lama é um indício de falha na política de segurança do trabalho e monitoramento da empresa.

Entretanto, as falhas técnicas apontam para questões estruturais, como a adoção de um modelo de desenvolvimento extrativista, dependente do setor mineral e de um Estado enfraquecido, facilitador dos interesses corporativos, que flexibiliza as leis ambientais e regulatórias e que permite práticas como automonitoramento das empresas ${ }^{3}$.

Passados mais de seis meses do ocorrido, a lama de rejeitos secou e tornou-se poeira, misturada à bruma que dá nome a cidade. A população segue em sofrimento crônico, agravado pelo sentimento de injustiça e sem número de incertezas. O setor público de saúde, ainda que tenha oferecido uma resposta rápida e eficiente, em médio e longo prazo, terá de lidar com demandas que ultrapassam suas condições normais de funcionamento e financiamento.
Nesse contexto, o seminário 'Desastre da Vale S.A. em Brumadinho: seis meses de impactos e ações', promovido pela Fundação Oswaldo Cruz (Fiocruz) nos dias 15 e 16 de agosto do ano de 2019, reuniu representantes de instituições do setor público em seus três níveis, de ensino e pesquisa, artistas e comunidade atingida, com o objetivo de oferecer um espaço para troca de experiências e informações, apontando para necessidade de promover políticas públicas que defendam os direitos da sociedade civil e do meio ambiente.

\section{Metodologia}

Esta produção é um relato de experiência de um grupo de estudantes do Curso de Especialização em Saúde Pública (Escola Nacional de Saúde Pública Sergio Arouca (Ensp/Fiocruz) e de uma pós-doutoranda em Saúde Coletiva (Instituto René Rachou - Fiocruz Minas), que participaram como relatoras do seminário 'Desastre da Vale S.A. em Brumadinho: seis meses de impactos e ações'. No decurso do evento, as estudantes trabalharam na síntese das discussões apresentadas nas sete mesas que o compuseram, buscando condensar a multiplicidade de temáticas que emergiram.

As mesas temáticas foram: Impactos e ações do SUS após o período mais imediato ao desastre; Desastres em barragens de mineração - riscos atuais e futuros; Ser atingido por barragens de mineração - situação atual e perspectivas futuras; As consequências sociais e econômicas dos desastres em barragens de mineração nos municípios atingidos; Modelo de desenvolvimento, desastres em barragens de mineração e impactos sobre a saúde; Riscos de desastres em barragens de mineração e sistemas de alerta e alarme - situação atual e propostas futuras; Desastres em barragens de mineração e violação de direitos.

Diante da abrangência dos debates apresentados e da impossibilidade de contemplar a todos para a produção desta publicação, optou-se pela estratégia de, a partir da análise do conteúdo, eleger três eixos centrais como itinerário para a escrita. Uma vez estabelecido o percurso desta 
produção, selecionaram-se as contribuições de pesquisadores e atingidos, presentes nas mesas citadas acima, que dialogassem com os eixos distribuídos nas seções.

Na primeira seção, discutem-se algumas das questões que produzem o risco estrutural de desastres, em tensão com o debate sobre os direitos humanos; na segunda, apresentam-se algumas das ações do sistema público de saúde, que precisou ser manejado a fim de responder às demandas emergentes, bem como estudos que versam sobre a toxicidade da água do Rio Paraopeba; na última seção, expõe-se uma argumentação sobre a importância de ver e ouvir a comunidade atingida, incluindo a poesia de um artista local.

As secções encontram-se demarcadas por fotografias de uma das autoras deste texto, que pode ausentar-se da tarefa de relatoria do evento, ocorrido na câmara municipal de Brumadinho, para uma visita à área rural do município. Considerou-se importante a apresentação desses registros ao longo do texto por se entender que as imagens igualmente comunicam e representam, neste caso, um importante aspecto da experiência vivida pelas estudantes, que acessavam o campo pela primeira vez.

O contato com o campo, o encontro com os personagens que estiveram presentes no seminário e o trabalho de relatoria das discussões mobilizaram as estudantes que, contagiadas pela atmosfera, utilizaram como recurso para apresentação dos resultados uma composição de trechos das falas de alguns dos debatedores presentes no encontro. A opção por esse recurso diz da intenção de fazer ouvir a multiplicidade de vozes que estiveram presentes na ocasião do seminário, objetivando trazer para a comunidade as experiências vividas durante o evento.

Essas falas foram transcritas a partir de vídeos feitos pela produção do evento, disponíveis publicamente no site YouTube. É possível encontrá-lo através do título do seminário 'Desastre da Vale S.A. em Brumadinho: seis meses de impacto e ações; 2019'.

Figura 1. Primeiro capítulo

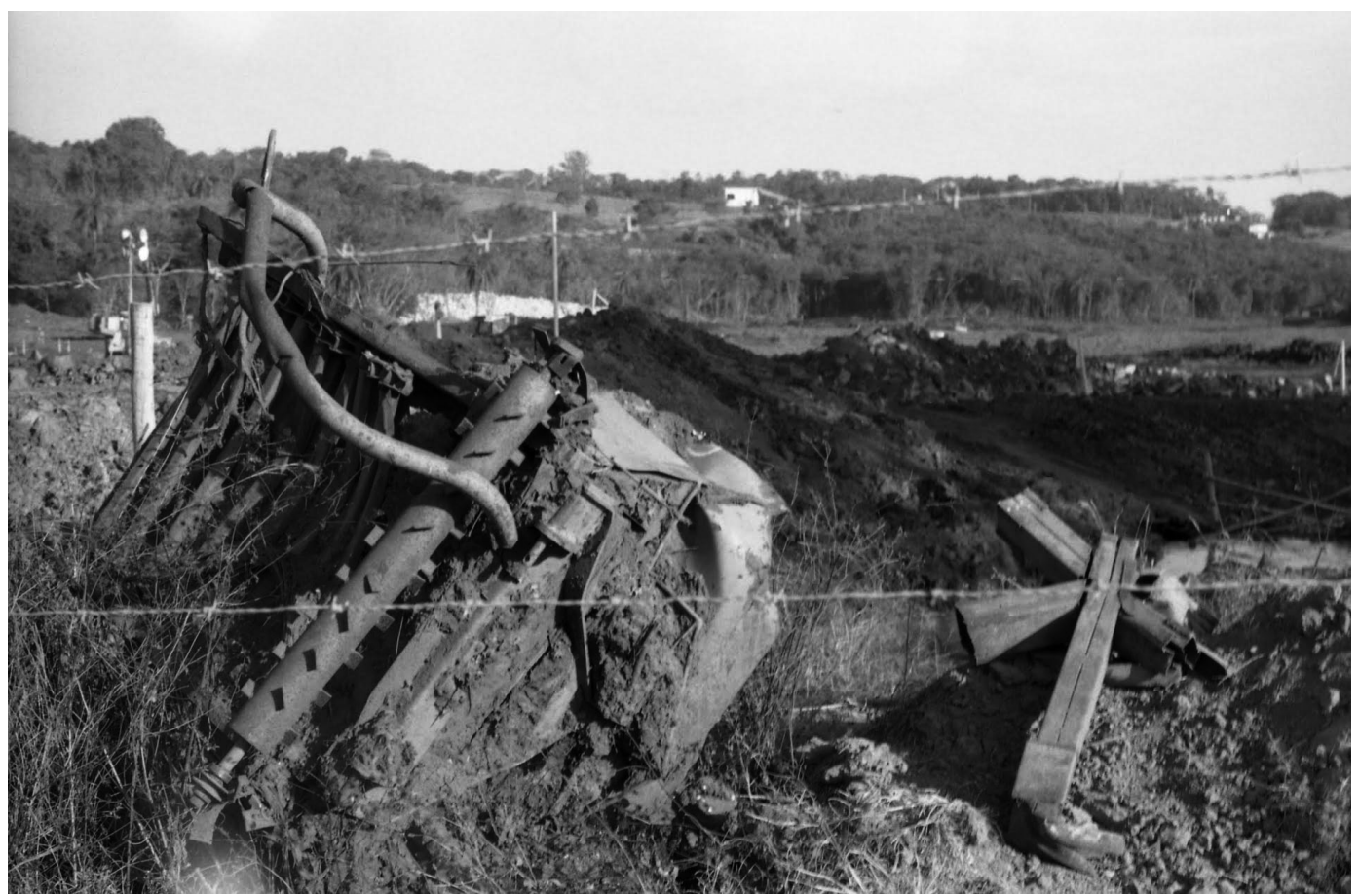

Fonte: Acervo de Giulia Balbi, também autora do texto. 


\section{Dos riscos estruturais}

O modelo de desenvolvimento capitalista, adotado pós-revolução industrial, aliado ao processo de globalização que coloca os países periféricos em situação de dependência econômica ante os países econômica e politicamente fortalecidos, favorece sua subordinação às empresas multinacionais. Tal fragilidade impede que os países periféricos consigam se posicionar e fazer frente a esse processo exploratório, flexibilizando as leis ambientais e trabalhistas que regulam a atuação das empresas e facilitando o interesse privado. Assim, a busca pelo progresso e pelo desenvolvimento, aliada à busca pelo crescimento econômico, fez com que muitos países admitissem a exploração predatória de seus recursos naturais e humanos ${ }^{4}$.

Sobre o enfraquecimento do poder do Estado, o geógrafo Milton Santos assinala:

Na medida em que aquele instituto encarregado de cuidar do geral é enfraquecido, estamos instalando, no território, uma fragmentação; estamos instalando, no território, um abandono da noção de solidariedade; estamos, pelo menos em médio prazo, produzindo as pré-condições da desordem ${ }^{5(6)}$.

Essa forma de exploração também desterritorializa parte da população quando não a coloca em situação de vulnerabilidade socioambiental, ampliando o risco à saúde devido ao contato com contaminantes químicos, físicos e biológicos. Cabe ressaltar que o risco gerado não é distribuído de forma equitativa; e as populações vulneráveis são as que mais sofrem as consequências desse modelo de desenvolvimento. Assim, questões como democracia, justiça social e ambiental, qualidade de vida e direitos humanos ficam subjugadas, aprofundando as desigualdades sociais, a degradação ambiental e configurando um cenário de risco estrutural de desastre, como apontou durante o Seminário a antropóloga Andréa Zhouri (Grupo de Estudos em Temáticas Ambientais - Gesta/Universidade Federal de Minas Gerasi - UFMG), mostrado no trecho abaixo:
Na perspectiva da Ecologia Política que orienta a nossa investigação, os desastres não são fenômenos naturais, são processos construídos socialmente... O desastre é processo! Gostaria de repetir aqui em bom tom: o desastre não é o rompimento da barragem, as pessoas confundem desastre com rompimento e chamam inclusive de 'evento', aquilo é um evento crítico dentro de um processo de desastre, que começa antes daquilo e tem continuidade ${ }^{6}$.

O processo de apropriação do território pelo desenvolvimento, seguido de desterritorialização, subtrai, também das populações tradicionais e locais, a capacidade de utilizarem seus saberes e práticas como ferramentas para a busca da sobrevivência, levando-as assim a buscar outras formas de vida que as distancia de suas culturas de origem. Em Brumadinho, "estima-se que há 147 e 424 comunidades (indígenas, quilombolas, silvicultores e pescadores artesanais) atingidas"1(2), além dos agricultores familiares. Nessa situação, há um sentimento de perda de identidade e pertencimento que perpassa essas populações, como expressou uma atingida, residente de Brumadinho, durante o Seminário:

Me perguntaram [sic], qual a proposta de vocês para a Vale, agricultores? Agricultor não sabe fazer mais nada, além de cuidar da terra [...]. Eu tenho filho que agora teve que trabalhar de outra forma, aprender outra profissão, eu tenho um filho que antes era agricultor e que agora teve que aprender a mexer com minério, né? Porque é o que temos agora?.

A fala acima transmite a perversidade relativa à conjuntura, situação na qual outras formas de subsistência acabam sufocadas pela dependência econômica da região do setor mineral, inclusive no momento pós-desastre, uma vez que a contaminação do Rio Paraopeba

inviabilizou seu uso para o consumo humano ou animal para irrigação, pesca, banho, entre outros danos diretos ou indiretos àqueles que se beneficiavam do uso da água2(1). 
Uma contradição presente no território é o fato de que o sistema de saúde do município pôde oferecer uma resposta rápida no pós-desastre, em parte, por conta dos impostos de compensação pagos pela atividade mineradora, que favoreceram a organização do sistema de saúde local e, ao mesmo tempo, expuseram a população ao risco de desastre.

O pesquisador Luiz Jardim (Poemas/ Universidade do Estado do Rio de Janeiro Uerj), presente no Seminário, debate a relação política da mineração com o poder público, deixando ver um Estado subjugado pela dependência econômica do setor mineral, mas também ativo, como facilitador dos interesses corporativos. Elenca uma série de mecanismos dessa porosidade público-privada, como o financiamento de campanhas e lobby em nível federal, a participação efetiva de seus representantes em conselhos ambientais, o recurso de "porta-giratória', entre outros. Sobre os possíveis benefícios econômicos da mineração ao município, adverte:

[...] Aí a gente pensa, bem, a mineração traz o emprego, a renda, e o município fica maravilhoso.
Não é bem assim, a faixa salarial fica em torno de 1 a 5 salários mínimos no setor extrativo em Brumadinho..., Mas, Brumadinho tem um dado que é alarmante, 33\% dos domicílios vivem com renda per capita menor do que meio salário mínimo! A mineração não tá trazendo essa receita toda para o município, sendo que ela tá operando 8 .

Pode-se dizer, assim, que o atual modelo de desenvolvimento, aliado à globalização, estimula a exploração de países econômica, política e socialmente mais fragilizados por empresas multinacionais, favorecendo a violação dos direitos humanos por parte das empresas e do próprio Estado ao não conseguir promover, proteger e garantir esses direitos.

Para além disso, é importante lembrar que, em 2015, os Estados-membros das Nações Unidas assinaram um Acordo Global pactuando objetivos a serem atingidos até 2030 que visavam erradicar a pobreza, proteger o Planeta e garantir que os indivíduos alcancem a paz e a prosperidade. No entanto, esses objetivos só serão atingidos se o atual modelo de desenvolvimento for repensado.

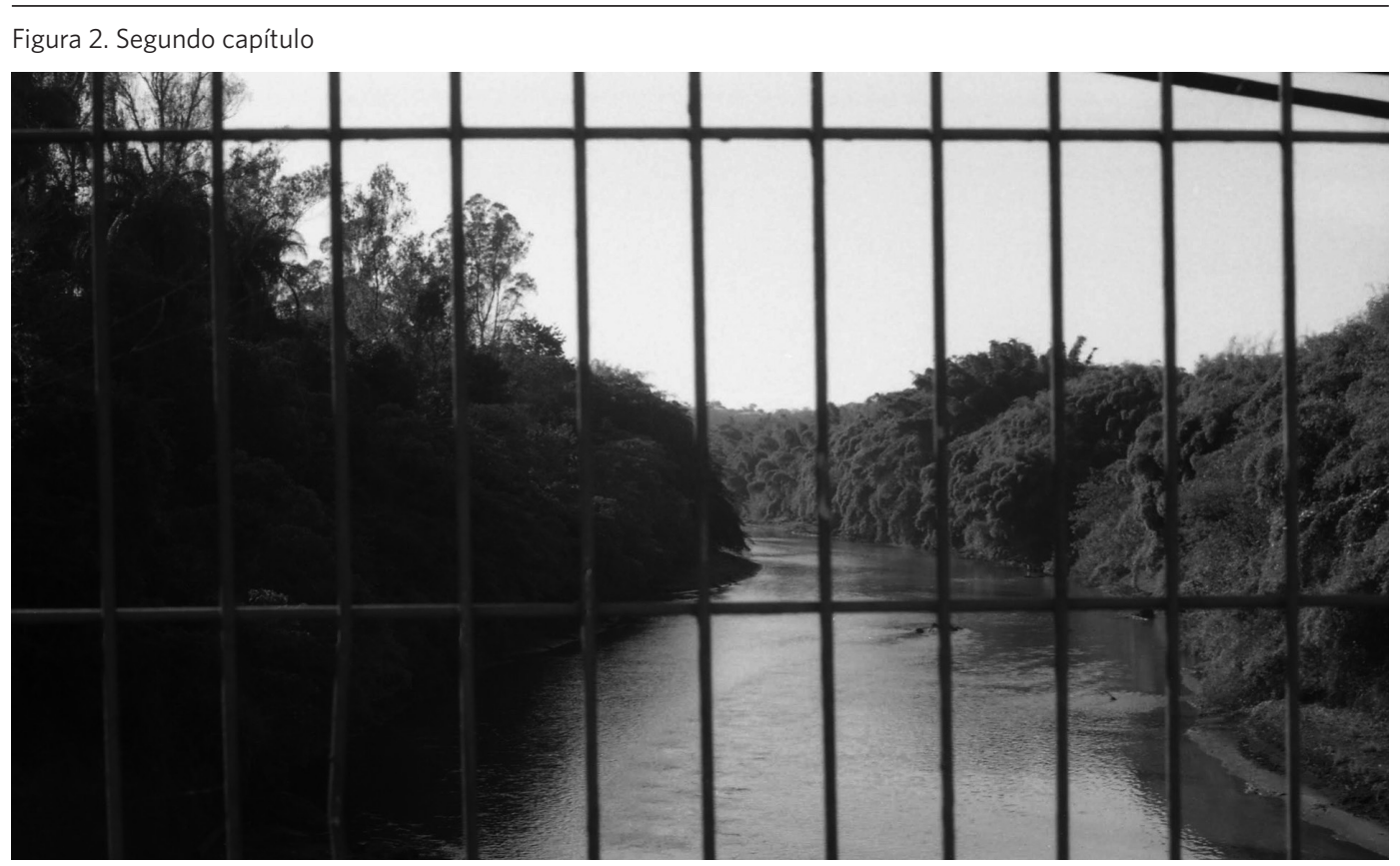

Fonte: Acervo de Giulia Balbi, também autora do texto. 


\section{Dos impactos sobre a saúde}

Tendo em vista o contexto histórico brasileiro, é possível observar como a organização política e econômica produz desigualdades socioambientais e influencia o risco estrutural de desastres em barragens de mineração. Nos últimos cinco anos, ocorreram, no estado de Minas Gerais, dois grandes rompimentos em localidades diferentes, causando impactos profundos e alterando não só as condições de vida da população atingida, mas também a organização econômico-financeira dos municípios.

Sendo assim, é importante que, após acontecimentos dessa magnitude, determinem-se quais os processos de gestão de risco antes, durante e após uma situação de desastre, estabelecendo-se os perigos aos quais a população está exposta e quais agravos podem incidir sobre a saúde da população, com a intenção de mitigá-los.

Durante o Seminário, observaram-se os esforços realizados pelos serviços de saúde pública para oferecer uma resposta rápida e eficiente à comunidade, instituindo um Centro de Operações Emergenciais nos conselhos de saúde em nível municipal, estadual e federal, com a finalidade de definir diariamente estratégias a serem executadas. Além disso, o município obteve apoio da Força Nacional do Sistema único de Saúde (SUS), Médicos Sem Fronteiras, Cruz Vermelha, Fiocruz, entre muitos voluntários e instituições.

No entanto, isso só foi possível porque, no momento do desastre, o território contava com um sistema de saúde pública estruturado e organizado, integralmente coberto pela Estratégia Saúde da Família (ESF), formado por 14 unidades e 2 equipes do Núcleo de Apoio à Saúde da Família (Nasf). Na média complexidade, o município contava com: Policlínica; Clínica de Fisioterapia; Centro de Atenção Psicossocial Infantil (Capsi); Centro de Atenção Psicossocial (Caps); Centro de Atenção Psicossocial para Álcool e outras Drogas (Caps AD); Núcleo de Práticas Integrativas e Complementares (Nupic);
Unidade de Pronto Atendimento (UPA) funcionando 24 h e um hospital de pequeno porte ${ }^{2}$.

No pós-desastre, o sistema de saúde do município foi manejado de acordo com as demandas emergentes, sofrendo alterações especialmente no que tange à atenção à saúde mental e psicossocial, em um contexto no qual o uso de ansiolíticos e antidepressivos aumentou em $60 \%$ e $80 \%$ respectivamente. Desse modo, o dispositivo de Caps 1 passou para nível 2, além do credenciamento do Capsi da rede de atenção do território, de modo a suprir as demandas previamente existentes, bem como as emergentes.

Ademais, três equipes de matriciamento em saúde mental foram formadas com o objetivo de serem itinerantes, ou seja, para estar presentes em todo o território, acolhendo sujeitos e coletando dados importantes para a reorganização desse sistema. As equipes de atenção primária também têm realizado um trabalho dentro da comunidade, tendo como intenção identificar os sinais de adoecimento da população e ofertando a possibilidade de acompanhamento no território, dispensando o sujeito da obrigatoriedade de frequentar um dispositivo de saúde.

Sobre as linhas de cuidado, José Geraldo, representante do Movimento dos Atingidos por Barragens (MAB), sinaliza uma aposta possível:

[...] queremos as práticas integrativas, cuidados populares e outras formas de cuidado que nos libertem da indústria da doença. Senão, além de romper a barragem e causar um crime, ainda vai dar lucro para indústria farmacêutica? .

Após o rompimento da barragem de rejeitos, a população atingida acabou exposta aos resíduos originários do processo produtivo da mineração, desde o contato direto com a lama até o consumo e a utilização da água contaminada. Além disso, depois que a lama dos rejeitos secou, tornou-se poeira e espalhou-se pela cidade, o que gera profunda incerteza quanto aos seus possíveis impactos sobre a 
saúde e preocupa a comunidade atingida.

Consequentemente, a análise da toxicidade dos agentes químicos, físicos e biológicos decorrentes desse processo é fundamental tanto para que seja possível dimensionar agravos e doenças que possam se manifestar no território quanto para orientar as ações longitudinais do SUS e para garantir a população o direito à informação precisa e adequada.

O processo de adoecimento por exposição a compostos químicos apresenta expressão multivariada e diversos determinantes. De acordo com o 'Manual de Epidemiologia Ambiental':

A suscetibilidade individual pode ser entendida como características inatas ou adquiridas que tornam um indivíduo mais ou menos sensíveis aos efeitos decorrentes da exposição a um intoxicante. Características genéticas podem tornar indivíduos mais ou menos tolerantes aos efeitos da exposição de um toxicante10(41).

A pesquisadora Mônica Lopes Ferreira (Instituto Butantan), presente no Seminário, apresentou uma pesquisa realizada em parceria com a Universidade Federal do Rio de Janeiro (UFRJ), em que se analisou a toxicidade da água do Rio Paraopeba em sete amostras coletadas entre os meses de fevereiro e julho de 2019. A análise detectou a presença de grande quantidade de ferro, alumínio e mercúrio; acrescente-se a isso o agravante de que a concentração desse último elemento estava 720 vezes acima do permitido para águas da classe $2^{4}$. Quando realizada análise metagenômica, detectou-se a presença de bactérias como salmonela e cianobactérias, que causam prejuízos à saúde humana.

Realizou-se um estudo usando o modelo Zebrafish em que tais peixes foram expostos a amostras da água do rio. O estudo revelou os seguintes resultados: atraso no desenvolvimento embrionário, escoliose, ausência de boca, edema pericárdico, hemorragia e mortalidade. Ressalta-se que esses peixes apresentam $70 \%$ de similaridade genética com a espécie humana e que, mesmo após a diluição da amostra em 650x, tais anomalias se manifestaram, alertando para desfechos negativos da exposição da população à lama e à água contaminada do Rio Paraopeba.

Após a apresentação da pesquisadora, uma representante da aldeia Pataxó se manifestou; sua fala foi seguida por aplausos da plateia:

[...] [sic] Quando eu falo nas minhas palestras que o rio está morto tem gente que ri da minha cara mas eu amei viu doutora porque eu não tenho um laboratório como a senhora mas eu tive a oportunidade de fazer a pesquisa dentro de uma caixa d'água sem produtos e os peixes nasceram tudo deformados e morreram com dois dias e eu me emocionei na fala da senhora à tarde ${ }^{\mathbf{1 1}}$.

A pesquisadora Carmem Froes (Instituto de Estudos em Saúde Coletiva - Iesc/UFRJ) debate sobre o sentido de saúde ampliada, em que o nexo causal não é suficiente para objetivar o impacto sobre a saúde, uma vez que uma multiplicidade de fatores psicossociais, econômicos e de exposição podem configurar riscos adicionais à realidade pós-desastre:

[...] Todo e qualquer processo de adoecimento, essa é a base que a gente trabalha, ela é consequente não só da exposição a um agente físico, a um agente químico ou a um agente biológico. Ela sempre foi, ela sempre vai ser do conjunto de condições econômicas, sociais, culturais, genéticas, ambientais de um município, de uma localidade, do lugar onde você vive. E isso vai interferir diretamente na percepção e condição de saúde dos indivíduos e na análise sobre as condições de saúde de uma população'12. 
Figura 3. Terceiro capítulo

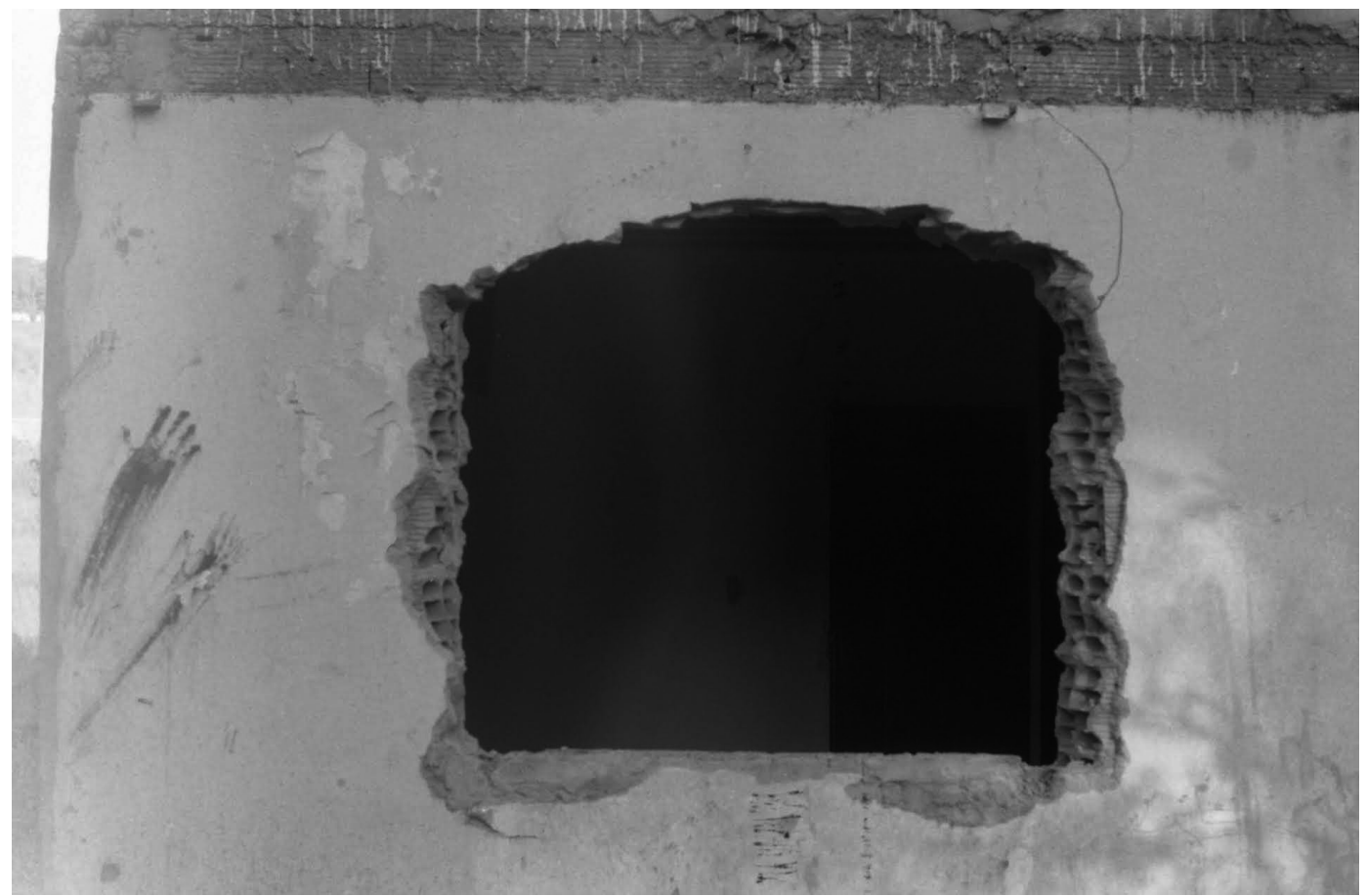

Fonte: Acervo de Giulia Balbi, também autora do texto.

\section{Ver e ouvir}

Após o desenvolvimento de diversos temas imprescindíveis para a discussão apresentada neste artigo, será feita uma reflexão acerca da importância de escutar a voz dos indivíduos atingidos pelo rompimento da barragem.

Utiliza-se a palavra 'atingido' como uma forma de referência a falas feitas pelas pessoas que tiveram a experiência de ter seus territórios e suas vidas modificadas pelo rompimento das barragens. Entendendo que esse acontecimento traz diversas versões e distintas análises, observa-se um impasse em relação aos termos utilizados para se referir às pessoas que vivem a situação. Segundo o 'Glossário de Proteção e Defesa Civil', que vem sendo referência para entender os riscos de desastre no Brasil, o termo utilizado para definir esses sujeitos é ‘afetado'. Para eles, "afetado é qualquer pessoa que tenha sido atingida ou prejudicada por desastre (deslocado, desabrigado, ferido etc.)"13(9).

Por outro lado, na comunidade científica, a expressão é definida de forma mais abrangente:

Para além dos números de 'afetados' tradicionalmente definidos pela Defesa Civil (desabrigados, desalojados, mortos, feridos e doentes) e registrados durante o período de resgate e socorro, deve-se considerar todos os que tiveram suas condições de vida e trabalho atingidas nos diferentes territórios ${ }^{\mathbf{1}(2)}$.

Para além de ter sua casa invadida pela lama ou da perda de um familiar, existem efeitos que se ampliam no espaço-tempo contínuo e irreparáveis danos provocados pela mudança social e ecológica naquele ambiente. 
No entanto, percebe-se que existem visões distintas provenientes de personagens diversos dentro desse contexto. Ser considerado um sujeito atingido ou um sujeito afetado faz diferença para aqueles que sofreram com o desastre. Dessa forma, dar visibilidade à fala desses indivíduos é fundamental para o relato proposto neste texto.

Quando se fala em trazer o discurso desses sujeitos, é preciso olhar para o conceito de lugar de fala, muito discutido pela filósofa Djamila Ribeiro. Com o objetivo de esclarecer uma questão central dentro dos movimentos sociais, a pensadora traz suas contribuições acerca deste. Segundo sua teoria,

'Lugar de fala' pode ser entendido como o ponto a partir do qual cada pessoa compreende o mundo e, portanto, constrói interpretações sobre o mesmo, faz pesquisas e produz conhecimento. Mais do que isso, destaca que a nossa forma de compreender o mundo é perpassada por elementos estruturais como por exemplo classe, raça e gênero ${ }^{\mathbf{1 4}(210)}$.

Seguindo esse raciocínio, portanto, e transportando-o para nossa discussão, é de extrema importância encarar as pessoas atingidas como detentoras de conhecimento e das necessidades existentes em suas vidas, devendo ser consideradas, isto é, vistas e ouvidas; indivíduos ativos no processo de gestão de riscos e reconstrução do território.

Sendo assim, entende-se o território como um conceito que ultrapassa o espaço físico, transformando-se em um espaço subjetivo constituído por processos sociais. Baseando-se na ideia de território-vivo de Milton Santos, "o território englobaria as características físicas de uma dada área, e também as marcas produzidas pelo homem"15(596). Ou seja, o território é definido como um todo dinâmico em que ocorrem interações econômicas, sociais e políticas. Ademais, nesse sentido, ele é entendido como um espaço no qual há uma troca de afetos materiais e imateriais.
É possível pensar na importância da construção de ciência e conhecimento engajados e comprometidos com o território, cultura e comunidade. Durante a abertura do Seminário, Zélia Profeta da Luz (Instituto René Rachou - Fiocruz Minas) sinaliza as potências de construir um debate que conte com as contribuições em abertura ao diálogo com a arte:

[...] E aí o motivo de colocar arte é pelo entendimento de que a arte nos ajuda muito nesses momentos, né? A arte tem o papel de transformação... Então a gente resolveu fazer essa discussão hoje e amanhã com os especialistas, mas também trazendo muita arte para nos ajudar a construir tudo isso ${ }^{16}$.

Posto isso, optou-se por expor aqui, a título de inspiração, um poema transcrito de uma declamação registrada em vídeo durante o Seminário de Sérgio Papagaio ${ }^{17}$, poeta e atingido pelo desastre da Samarco em Mariana.

Minas será plana

Não terá mais

O encanto das montanhas

Suas águas turvas

Suas estradas sem curvas

Seus mistérios desvendados

Seus sonos transbordados

Seu povo transtornado

Afugentado

Aterrorizado

Nivelada a linha do horizonte

Pois o diabo comerá seus montes

Minas virará um grande lingote

De ferro maciço

Uma barra de ouro misto

Ao som do povo

Entoando um grito de socorro

Sob o domínio da Vale

Com seu tridente

Mina agora doente

Mandará para o mar

$O$ resto que sobrar

Do verbo minerar 


\section{Conclusões}

Os desastres em barragens de mineração, resultantes de falhas técnicas e processos históricos e estruturais, configuram um enorme desafio à saúde coletiva, uma vez que expõem população e ambiente a riscos multifacetados que se sobrepõem, desde o contato com agentes tóxicos presentes nos rejeitos de mineração até sentimentos disruptivos de perda de identidade e memória comunitária, desorganização financeira do município, entre tantos outros. Desse modo, produzem agravos que se manifestam de modo imediato, mas também de forma longitudinal, no decorrer do tempo, sobrepujando as condições de funcionamento do sistema de saúde do município.

Seis meses após o desastre da Vale S.A. em Brumadinho, e quatro anos depois do desastre da Samarco em Mariana, está nítida a necessidade de reflexão sobre o modelo de desenvolvimento adotado no País, que enfraquece o poder do Estado e gera desigualdades socioambientais e riscos aos direitos humanos.

A despeito disso, o seminário 'Desastre da Vale S.A. em Brumadinho: seis meses de impactos e ações' aponta outro caminho possível: a partir da escuta ativa dos atores envolvidos no processo, participação dos atingidos, do emprego da arte - esta que deixa ver o sofrimento advindo do processo de desastres
- em diálogo com uma ciência engajada e solidária. Ainda, esta reunião facilita a articulação do setor público, favorecendo as condições para que este cobre da empresa suas responsabilidades.

\section{Colaboradoras}

Costa GBR (0000-0003-0523-4511)* contribuiu para o planejamento, elaboração do rascunho, revisão crítica do conteúdo e aprovação da versão final do manuscrito. Lau GR (00000003-4116-6755)* contribuiu substancial para a concepção e o planejamento; elaboração do rascunho; e participação da aprovação da versão final do manuscrito. Silva CF (00000002-5072-2744)* contribuiu para a concepção; análise de dados e elaboração do rascunho do manuscrito. Mantel MCB (0000-00017838-759X)* contribuiu para a concepção; planejamento e elaboração do rascunho do manuscrito. Peres MCM (0000-0002-5317-8465)* contribuiu para aconcepção; interpretação dos dados e elaboração do rascunho do manuscrito. Luna TNSS (0000-0002-9697-5640)* contribuiu para a concepção, planejamento e elaboração do rascunho do manuscrito. Silva PN (0000-0001-8909-4477)* contribuição para o planejamento, análise de dados e elaboração do rascunho do manuscrito.
*Orcid (Open Researcher and Contributor ID).

\section{Referências}

1. Freitas CM, Barcellos C, Asmus CIRF, et al. Da Samarco em Mariana à Vale em Brumadinho: desastres em barragens de mineração e Saúde Coletiva. Cad. Saúde Pública [internet]. 2019 [acesso em 2019 jun 30]; 35(5):1-7. Disponível em: https://www.scielosp. org/article/csp/2019.v35n5/e00052519/.
2. Silva Noal D, Rabelo IVM, Chachamovich E. O impacto na saúde mental dos afetados após o rompimento da barragem da Vale. Cad. Saúde Pública [internet]. 2019 [acesso em 2019 jun 30]; 35(5):1-3. Disponível em: http://www.scielo.br/scielo.php?script=sci_ arttext\&pid= S0102-311X2019000600503. 
3. Milanez B, Magno L, Pinto RG. Da política fraca à política privada: o papel do setor mineral nas mudanças da política ambiental em Minas Gerais, Brasil. Cad. Saúde Pública [Internet]. 2019 [acesso em 2020 jan 22]; 35(5):e00051219. Disponível em: http://dx.doi. org/10.1590/0102-311x00051219.

4. Grisul U. PACHA: Defendendo a Terra: Extrativismo, conflitos e alternativas na América Latina e no Caribe [internet]. 2018. [acesso em 2019 jun 25]. Disponível em: http://www.grisulunirio.com/wp-content/ uploads/2018/11/Cartilha_Final_Internet-Port.pdf.

5. Santos M. Da Política dos Estados À Política Das Empresas. Cad. Esc. Legisl. 1997; 3(6):1-9.

6. Zhouri A. Seminário Desastres da Vale S.A. em Brumadinho: seis meses de impacto e ações 2019, parte 4. [vídeo] [internet]. [acesso em 2019 set 3]. Disponível em: https://www.youtube.com/watch?v=sl5Cq7egrhM.

7. Campos S. Seminário Desastres da Vale S.A. em Brumadinho: seis meses de impacto e ações; 2019, parte 2. [vídeo] [internet]. [acesso em 2019 set 3]. Disponível em: https://www. youtube.com/watch?v=3TQVHvZQCSs.

8. Jardim L. Seminário Desastres da Vale S.A. em Brumadinho: seis meses de impacto e ações; 2019, parte 2. [vídeo] [internet]. [acesso em 2019 set 3]. Disponível em: https://www.youtube.com/ watch? $=\mathrm{cXBwOyH} 58 \mathrm{Qc} \& \mathrm{t}=8616 \mathrm{~s}$.

9. Geraldo J. Seminário Desastres da Vale S.A. em Brumadinho: seis meses de impacto e ações; 2019, parte 4. [vídeo] [internet]. [acesso em 2019 set 3]. Disponível em: https://www.youtube.com/watch?v=sl5Cq7egrhM.

10. Braga ALF, Pereira LAA, Martins LC, et al. Manual de Epidemiologia Ambiental [internet]. Santos: Puc-Santos; 2015. [acesso em 2019 set 3]. Disponível em: https://www.unisantos.br/wp-content/uploa-
ds/2018/05/Vigilancia-saude-ambiental-superior.

pdf.

11. Peixoto C. Seminário Desastres da Vale S.A. em Brumadinho: seis meses de impacto e ações; 2019, parte 2. [vídeo] [internet]. [acesso em 2019 set 3]. Disponível em: https://www.youtube.com/ watch?v=3TQVHvZQCSs\&t=9551s.

12. Froes C. Seminário Desastres da Vale S.A. em Brumadinho: seis meses de impacto e ações; 2019, parte 2. [vídeo] [internet]. [acesso em 2019 set 3]. Disponível em: https://www.youtube.com/ watch?v=3TQVHvZQCSs\&t=9551s .

13. Secretaria Nacional de Proteção e Defesa Civil. Manual de Proteção e Defesa Civil. Brasília, DF: Sedec; 2017.

14. Kyrillos GM. "O que é Lugar de Fala?" De Djamila Ribeiro. Cap. Críptica. 2018; 7(1):209-214.

15. Araújo Lima EMF, Yasui S. Territórios e sentidos: espaço, cultura, subjetividade e cuidado na atenção psicossocial. Saúde debate. 2014; 38(102):593-605.

16. Luz ZP. Seminário Desastres da Vale S.A. em Brumadinho: seis meses de impacto e ações; 2019, parte 1. [vídeo] [internet]. [acesso em 2019 set 3]. Disponível em: https://www.youtube.com/watch?v=op_350lXdjs.

17. Papagaio C. Desastres da Vale S.A. em Brumadinho: seis meses de impacto e ações; 2019. [vídeo] [internet]. [acesso em 2019 set 3]. Disponível em: https:// www.youtube.com/watch?v=Z4fB9uLlwVo\&featur e=youtu.be.

\footnotetext{
Recebido em 30/09/2019

Aprovado em 10/03/2020

Conflito de interesses: inexistente

Suporte financeiro: não houve
} 